\title{
CONSERVAÇÃO DAS FLORESTAS NA BACIA DO ALTO IGUAÇU, PARANÁ - AVALIAÇÃO DA COMUNIDADE DE EPÍFITAS VASCULARES EM DIFERENTES ESTÁGIOS SERAIS
}

\author{
Rodrigo de Andrade Kersten ${ }^{1}$, Yoshiko Saito Kuniyoshi ${ }^{2}$ \\ ${ }^{1}$ Biólogo, Dr., Pontifícia Universidade Católica, PUC-PR, Curitiba, PR, Brasil - kersten@ pop.com.br \\ ${ }^{2}$ Naturalista, Dr ${ }^{\mathrm{a}}$., Depto. de Ciências Florestais, UFPR, Curitiba, PR, Brasil - yoshiko@ufpr.br
}

Recebido para publicação: 25/01/2008 - Aceito para publicação: 06/05/2008

\begin{abstract}
Resumo
Com o intuito de avaliar o grau de conservação das florestas ribeirinhas da bacia do rio Iguaçu no Primeiro Planalto Paranaense, foi realizado o levantamento qualitativo de epífitas vasculares em oito estações de Floresta Ombrófila Mista nesse planalto, seis localizadas em planícies aluviais e duas em encostas. Para o levantamento quantitativo, foram consideradas duas seres, inicial e média, com 50 forófitos levantados em cada uma. Foi utilizada divisão da árvore em 'zonas ecológicas' e atribuição de notas relativas à abundância das espécies nesses intervalos. O valor de importância foi calculado sobre a frequência nos forófitos e a dominância. Foram observadas 114 espécies (duas exóticas) de epífitas vasculares distribuídas em 52 gêneros e 20 famílias. A riqueza florística nos sítios variou de 29 a 83 espécies. Duas espécies dominam o ambiente, Microgramma squamulosa e Pleopeltis pleopeltifolia, com valor de importância bem superior ao das demais. As florestas em estágio inicial de sucessão apresentaram menor riqueza florística e diversidade ecológica que as em estágio médio. O número de espécies sobre forófitos variou de dois a dezessete. Foram estabelecidos três grupos sucessionais de espécies epífitas: pioneiras, secundárias e avançadas. As florestas foram consideradas fortemente perturbadas. As estações de floresta de encosta foram mais ricas que as de planície, estando, aparentemente, mais conservadas. As estações mais ricas são também as florestas mais desenvolvidas e menos visitadas pela população, indicando que a manutenção de indivíduos arbóreos ajuda a manter a diversidade e a abundância da flora epífita.
\end{abstract}

Palavras-chave: Epífitas vasculares; Floresta Ombrófila Mista; estrutura; sucessão.

\begin{abstract}
Forest conservation on the Iguaçu river basin, Paraná - evaluation of the vascular epiphyte community in different seres. Aiming analyze the conservation of the riverside forest on the Iguaçu river basin Eigth areas (six on floodplains and two on hillsides) were surveyed for the vascular epiphyte checklist. On the floodplains sites 100 trees were selected for the structural survey on two succession stages (initial and medium). The trees were divided into three zones. Dominance was estimated in each zone by scores for each species. The importance index was calculated from the frequency on the trees and the dominance. We found 114 species (two aliens) on 52 genera and 20 families. On the sites we found from 29 to 83 species. Most of the species were chacteristic holoepiphytes (89\%). Microgramma squamulosa and Pleopeltis pleopeltifolia were the most important species. On the host trees epiphyte species number varied from two to 17 . The forest considered to be initial succession presented lower species and ecological diversity than the forests considered medium succession. Three successional categories were established (early, intermediate and late succession species). All the forests were considered highly disturbed. The hillside forests were more species-diverse than the floodplain and apparently are better conserved. The floristic composition and the structure were uniform along the area; the most diverse sites were also more developed and less people-visited indicating that the maintenance of old trees is important to the diversity of the epiphytic flora.

Keywords: Vascular epiphytes; Floresta Ombrófila Mista; structure; succession.
\end{abstract}

\section{INTRODUÇÃO}

Com superfície total de $201.203 \mathrm{~km}^{2}$, o Paraná situa-se quase inteiramente ao sul do trópico de Capricórnio. Pode ser dividido em cinco regiões naturais: litoral, Serra do Mar e os três planaltos do 
interior. Sua paisagem original foi dominada por formações florestais que cobriram $85 \%$ do território, sendo os 15\% restantes cobertos por campos e várzeas (MAACK, 1968).

O Primeiro Planalto é dividido segundo as bacias do Iguaçu (sul), chamado de planalto de Curitiba, e do Ribeira (norte). A região sul, com altitude regular, forma paisagem suave, com amplas planícies de várzeas. É formada, basicamente, por rochas antigas do complexo granulítico de Santa Catarina/Serra Negra, intercaladas por sedimentos fluviais e paludais. (MAACK, 1968).

Os rios do Paraná pertencem a duas bacias principais: Atlântica e do Paraná, sendo a última a mais importante. Fazem parte desse sistema os rios Iguaçu, Ivaí, Piquiri e Tibagi e respectivas bacias. A bacia do Iguaçu é a maior do estado. Tem suas nascentes localizadas na Serra do Mar e, após percorrer o estado inteiro, deságua no rio Paraná, em Foz do Iguaçu, fazendo a divisa do Brasil com a Argentina (MAACK, 1968).

As florestas ribeirinhas desempenham importante função ecológica e hidrológica, contribuindo para regularizar os regimes hídricos, para manter a qualidade da água, para estabilizar o solo, para auxiliar na ciclagem de nutrientes, para a estabilidade térmica e para o escoamento das águas pluviais, além de contribuir para a alimentação e abrigo da fauna (BARBOSA, 1989; LIMA; ZÁKIA, 2000; VAN DEN BERG; OLIVEIRA FILHO, 2000; CIRELLI; PENTEADO-DIAS, 2003). Podem tanto ocorrer em planícies de inundação como em encostas, rochosas ou não. Nas planícies, a vegetação sofre influência direta tanto do rio, pelo encharcamento do solo, como pela atuação da correnteza. Essas características fazem com que fisionomicamente essas florestas apresentem convergência em seus caracteres estruturais (CURCIO, 2006).

Aproximadamente $10 \%$ de todas as plantas vasculares são epífitas (KRESS, 1986), sendo encontradas quase exclusivamente em florestas tropicais, chegando a representar mais de $25 \%$ das espécies em muitos países (NIEDER et al., 2001). A dependência da umidade atmosférica faz com que a flora epifítica tenha seus centros de diversidade localizados nas regiões ou florestas úmidas do globo (GENTRY; DODSON, 1987). Essa sensibilidade à umidade, associada à dependência de substrato arbóreo, faz com que as epífitas sejam bons indicadores ecológicos, registrando tanto a qualidade e estágio dos ecossistemas quanto as variações ambientais naturais (TRIANA-MORENO et al., 2003).

Dentre os trabalhos realizados sobre epífitos vasculares observados em todo o mundo, a maioria foi realizada nas regiões tropicais, notadamente nos neotrópicos. No Brasil existem relativamente poucos estudos que tratam da composição florística e da distribuição espacial de epífitas vasculares, a grande maioria realizada nas regiões Sul e Sudeste. Na região de ocorrência da Floresta Ombrófila Mista, podem ser citados, ao todo, quatro estudos (CERVI; DOMBROWISKI, 1985; CERVI et al., 1988; DITTRICH et al., 1999; BORGO; SILVA, 2003), que, somados, listam 115 espécies.

Este estudo teve como objetivo avaliar a composição e distribuição dos epífitos vasculares nas florestas da bacia do rio Iguaçu no Primeiro Planalto Paranaense, bem como analisar a estrutura da comunidade epífita vascular em diferentes seres de regeneração de suas florestas ribeirinhas.

\section{METODOLOGIA}

Foi realizado o levantamento qualitativo em oito estações de Floresta Ombrófila Mista (FOM) no Primeiro Planalto Paranaense, distribuídas conforme tabela 1. Seis estações estão localizadas às margens de rios (floresta ribeirinhas), em planície aluvial, e duas estão localizadas fora dessa zona, sendo denominadas de encosta. Não foram consideradas localidades no município de Curitiba, por já ter sido suficientemente amostrado por Cervi; Dombrowiski (1985), Cervi et al. (1988), Dittrich et al. (1999) e Borgo; Silva (2003).

Foi coletado um exemplar de cada espécie encontrada fértil para registro em herbário, com exceção de espécies muito comuns. O material coletado foi identificado com o auxílio de literatura especializada, comparação com material já depositado nos herbários UPCB e MBM e consulta a especialistas. Todo o material foi herborizado segundo procedimentos usuais em trabalhos florísticos e tombado nos herbários UPCB, MBM ou EFC. Os nomes das espécies foram verificados no W3tropicos (2006). As angiospermas foram organizadas segundo o sistema APG (STEVENS, 2006) e as pteridófitas segundo Smith et al. (2006). Pleurothallis (Orchidaceae), não obstante existência de publicações sugerindo sua divisão, foi tratado como gênero único.

As comparações florísticas entre diferentes localidades foram feitas a partir do índice de Jaccard, sempre atualizando-se a nomenclatura entre as listagens e desconsiderando-se espécies exóticas ou introduzidas. Foi também calculada a diversidade $\beta$ de Harrison (MAGURRAN, 2004). 
Tabela 1. Estações amostrais no Primeiro Planalto Paranaense por tipologia considerada (município em que se localiza, altitude, área aproximada e estágio seral).

Table 1. Study sites in the Curitiba plateau separated by Forest type (county, altitude, area, succession seres).

\begin{tabular}{lccccc}
\hline Subformação & Local & Município & Altitude & Área (ha) & Estágio \\
\hline Planície & Campina & Araucária & 885 & 3,5 & Inicial \\
& Guajuvira & Araucária & 880 & 4,5 & Inicial \\
& General Lúcio & Araucária & 875 & 6,3 & Médio/Inicial \\
& Balsa Nova & Balsa Nova & 865 & 4,8 & Médio/inicial \\
& Barigui & Araucária & 890 & 10,0 & Médio \\
& Araucária & Araucária & 890 & 4,0 & Médio \\
Encosta & Pinhais & Pinhais & 950 & 9,3 & Médio \\
& Contenda & Contenda & 900 & 11,5 & Médio \\
\hline Total & & & 53,9 & \\
\hline
\end{tabular}

A partir da observação em campo, as espécies foram classificadas em cinco categorias ecológicas, de acordo com sua relação com a árvore suporte (BENZING, 1990): Holoepífito característico, holoepífito facultativo, holoepífito acidental, hemiepífito primário e hemiepífito secundário.

Para avaliação da comunidade de epífitas em diferentes seres, foi realizado um levantamento quantitativo considerando apenas as estações ribeirinhas. O estágio de regeneração (seral) de cada floresta foi definido com base na vegetação arbórea. Foram reconhecidos três estágios: inicial, médio inicial e médio. Não foram encontradas áreas em estágio avançado de regeneração. Em cada um dos estágios inicial e médio foram levantados 50 forófitos. Foi adotado o método proposto por Braun-Blanquet (1979) de divisão da árvore em 'zonas ecológicas' e atribuição de notas (1 a 3) relativas à abundância das espécies (indivíduos ou grupamentos) nesses intervalos. Dividiu-se a árvore em três zonas - fuste baixo (primeiro 1,3 m próximo ao solo), fuste alto (de 1,3 $\mathrm{m}$ até a base da copa) e copa (acima do ponto de inversão morfológica) - e foi considerado indicativo de suficiência amostral a estabilização da curva do valor de importância das 15 espécies com maior importância. Baseando-se nas estimativas de abundância e distribuição das espécies nas estações em diferentes estágios de regeneração, foram definidos grupos com as espécies epifíticas consideradas características dessas formações: pioneiras, secundárias e avançadas.

$\mathrm{O}$ valor de importância epifítico (VIE) foi calculado sobre a frequência nos forófitos e a dominância específica, conforme fórmulas: VIE $=(\operatorname{DoR}+\mathrm{FfR}) / 2 ;$ DoR $=100\left(\mathrm{DoA} / \sum \mathrm{DoA}\right) ; \mathrm{FfR}=$ $100\left(\mathrm{FfA} / \sum \mathrm{FfA}\right) ; \mathrm{FfA}=100$ (nfe/ntf), em que DoR = dominância relativa, $\mathrm{FfR}=$ frequência relativa sobre os forófitos, DoA = dominância absoluta, FfA = frequência absoluta sobre os forófitos, nfe = número de forófitos que abrigam a espécie epifítica e ntf = número total de forófitos. Foi calculada também a dominância total de cada estágio seral, a partir da soma de todas as notas atribuídas aos indivíduos ou grupamentos analisados. Foram calculados os índices de diversidade de Shannon (H'), Equidade (J'), McIntosh (D) e Simpson (D), além do índice de riqueza de Margalef $\left(\mathrm{D}_{\mathrm{Mg}}\right)$. Para o cálculo desses índices, como tradicionalmente considerado em estudos sobre epífitas vasculares (WAECHTER; BAPTISTA, 2004), substituiu-se o número de indivíduos pelo número de indivíduos forofíticos em que a espécie foi registrada. Com base na frequência forofítica e no valor de importância, foi aplicado o teste de Kolmogorov-Smirnov (MAGURRAN, 2004), para verificar diferença na abundância entre os estágios serais.

Nos estudos quantitativos Oncidium raniferum, O. longicornu e $O$. paranaense foram tratadas como morfoespécies (Oncidium spp.), por serem similares quando em fase vegetativa.

\section{RESULTADOS}

Foram observadas, nas oito estações, 114 espécies de epífitas vasculares (Tabela 2), distribuídas em 52 gêneros e 20 famílias. As pteridófitas contribuíram com 31 espécies (27\%), enquanto as angiospermas somaram 83 espécies, sendo quatro espécies de magnoliides, 14 espécies (12\%) de eudicotiledôneas e 65 espécies (57\%) de monocotiledôneas. Duas espécies exóticas (Impatiens walleriana e Ligustrum lucidum) foram registradas. 
Tabela 2. Lista das espécies observadas na região do Primeiro Planalto Paranaense, seguidas da categoria ecológica de relação com o forófito $(\mathrm{HM}=$ hemiepífito, $\mathrm{S}=$ secundário, $\mathrm{P}=$ Primário; $\mathrm{HL}=$ holoepífito, $\mathrm{O}=$ característico, $\mathrm{F}$ = facultativo, $\mathrm{A}$ = acidental) e estágio seral de ocorrência (Enc - Encosta em sucessão média; In - Planície em sucessão inicial; MI - Planície em sucessão média-inicial; M - Planície em sucessão média).

Table 2. Vascular epiphyte checklist in the Curitiba plateau by vegetation type and succession seres (Enc - mid-succession hill; In - early-succession river plain; MI - early to mid-succession river plain; $\mathrm{M}$-mid-succession river plain), the categories based o the relationship to the host $(\mathrm{HM}=$ hemiepiphytic, $\mathrm{S}=$ secondary, $\mathrm{P}=$ primary; $\mathrm{HL}=$ holoepiphyte, $\mathrm{O}=$ truly, $\mathrm{F}=$ facultative, $\mathrm{A}=$ accidental) is also indicated.

\begin{tabular}{|c|c|c|c|c|c|c|}
\hline $\begin{array}{l}\text { FAMÍLIA } \\
\text { (número de espécies) }\end{array}$ & Espécie & Categoria & Enc & In & MI & $\mathbf{M}$ \\
\hline ARACEAE (1) & Philodendron loefgrenii Engl. & HMS & $\mathrm{x}$ & & $\mathrm{x}$ & $\mathrm{x}$ \\
\hline \multirow[t]{4}{*}{ ASPLENIACEAE (4) } & Asplenium clausenii Hieron. & HLA & & & & $\mathrm{x}$ \\
\hline & Asplenium gastonis Fée & HLP & $\mathrm{x}$ & & $\mathrm{x}$ & $\mathrm{x}$ \\
\hline & Asplenium harpeodes Kunze & HLP & $\mathrm{x}$ & & & \\
\hline & Asplenium incurvatum Fée & HLP & & & $\mathrm{x}$ & \\
\hline BALSAMINACEAE (1) & Impatiens walleriana Hook. f. & HLF & & & & $\mathrm{x}$ \\
\hline BLECHNACEAE (1) & Blechnum binervatum (Poir.) C. V. Morton e Lellinger & HMS & $\mathrm{x}$ & & & \\
\hline \multirow[t]{14}{*}{ BROMELIACEAE (14) } & Aechmea distichantha Lem. & HLP & $\mathrm{x}$ & $\mathrm{x}$ & $\mathrm{x}$ & $\mathrm{x}$ \\
\hline & Aechmea recurvata (Klotzsch.) L. B. Sm. & HLO & $\mathrm{x}$ & & $\mathrm{x}$ & $\mathrm{x}$ \\
\hline & Billbergia nutans $\mathrm{H}$. Wendl. & HLO & $\mathrm{x}$ & & $\mathrm{x}$ & \\
\hline & Tillandsia crocata (E. Morren) Baker & HLO & & & & $\mathrm{x}$ \\
\hline & Tillandsia linearis Vell. & HLO & & $\mathrm{x}$ & $\mathrm{x}$ & \\
\hline & Tillandsia mallemontii Glaziou ex Mez & HLO & & $\mathrm{x}$ & $\mathrm{x}$ & $\mathrm{x}$ \\
\hline & Tillandsia recurvata $(\mathrm{L}.) \mathrm{L}$. & HLO & & $\mathrm{x}$ & $\mathrm{x}$ & $\mathrm{x}$ \\
\hline & Tillandsia stricta Sol. & HLO & $\mathrm{x}$ & $\mathrm{x}$ & $\mathrm{x}$ & $\mathrm{x}$ \\
\hline & Tillandsia tenuifolia $\mathrm{L}$. & HLO & $\mathrm{x}$ & $\mathrm{x}$ & $\mathrm{x}$ & $\mathrm{x}$ \\
\hline & Tillandsia usneoides $\mathrm{L}$. & HLO & $\mathrm{x}$ & $\mathrm{x}$ & $\mathrm{x}$ & $\mathrm{x}$ \\
\hline & Vriesea friburgensis $\mathrm{Mez}$ & HLO & $\mathrm{x}$ & & & $\mathrm{x}$ \\
\hline & Vriesea philippocoburgi Wawra & HLO & $\mathrm{x}$ & $\mathrm{x}$ & & $\mathrm{x}$ \\
\hline & Vriesea platynema Gaudich. & HLO & & & & $\mathrm{x}$ \\
\hline & Vriesea reitzii Leme e A. Costa & HLO & & & & $\mathrm{x}$ \\
\hline \multirow[t]{8}{*}{ CACTACEAE (8) } & Hatiora salicornioides (Haw.) Britton e Rose & HLO & $\mathrm{x}$ & & & $\mathrm{x}$ \\
\hline & Lepismium cruciforme (Vell.) Miq. & HLO & $\mathrm{x}$ & & & $\mathrm{x}$ \\
\hline & Lepismium houlletianum (Lem.) Barthlott & HLO & $\mathrm{x}$ & & $\mathrm{x}$ & $\mathrm{x}$ \\
\hline & Lepismium lumbricoides (Lem.) Barthlott & HLO & $\mathrm{x}$ & $\mathrm{x}$ & $\mathrm{x}$ & $\mathrm{x}$ \\
\hline & Rhipsalis campos-portoana Loefgr. & HLO & $\mathrm{x}$ & $\mathrm{x}$ & $\mathrm{x}$ & \\
\hline & Rhipsalis floccosa Salm-Dyck ex Pfeiff. & HLO & $\mathrm{x}$ & $\mathrm{x}$ & & $\mathrm{x}$ \\
\hline & Rhipsalis neves-armondii K. Schum. & HLO & & $\mathrm{x}$ & $\mathrm{x}$ & $\mathrm{x}$ \\
\hline & Rhipsalis teres (Vell.) Steud. & HLO & & $\mathrm{x}$ & $\mathrm{x}$ & $\mathrm{x}$ \\
\hline \multirow[t]{2}{*}{ COMMELINACEAE (2) } & Commelina robusta Kunth. & HLA & $\mathrm{x}$ & & & \\
\hline & Tradescantia fluminensis Vell. & HLA & $\mathrm{x}$ & & & $\mathrm{x}$ \\
\hline DRYOPTERIDACEAE (1) & Rumohra adiantiformis (G. Forst.) Ching & HLP & $\mathrm{x}$ & & & $\mathrm{x}$ \\
\hline \multirow[t]{2}{*}{ GESNERIACEAE (2) } & Nematanthus wettsteinii (Fritsch) H. E. Moore & HLO & $\mathrm{x}$ & & & \\
\hline & Sinningia douglasii (Lindl.) Chautems & HLO & $\mathrm{x}$ & & & $\mathrm{x}$ \\
\hline \multirow[t]{4}{*}{ HYMENOPHYLLACEAE (4) } & Hymenophyllum polyanthos (Sw.) Sw. & HLO & $\mathrm{x}$ & & & $\mathrm{x}$ \\
\hline & Trichomanes capillaceum $\mathrm{L}$. & HLO & $\mathrm{x}$ & & & \\
\hline & Trichomanes hymenoides Hedw. & HLO & & & & $\mathrm{x}$ \\
\hline & Trichomanes pyxidiferum $\mathrm{L}$. & HLO & $\mathrm{x}$ & & $\mathrm{x}$ & \\
\hline LYCOPODIACEAE (1) & Huperzia heterocarpon (Fée) Holub & HLO & $\mathrm{x}$ & & & \\
\hline MORACEAE (1) & Ficus luschnathiana (Miq.) Miq. & HMP & $\mathrm{x}$ & & & \\
\hline OLEACEAE (1) & Ligustrum lucidum W. T. Aiton & HLA & & & & $\mathrm{x}$ \\
\hline \multirow[t]{2}{*}{ ORCHIDACEAE (48) } & Barbosella australis (Cogn.) Schltr. & HLO & $\mathrm{x}$ & & & $\mathrm{x}$ \\
\hline & Bulbophyllum granulosum Barb. Rodr. & HLO & $\mathrm{x}$ & & & \\
\hline
\end{tabular}




\begin{tabular}{|c|c|c|c|c|c|c|}
\hline & Campylocentrum aromaticum Barb. Rodr. & HLO & $\mathrm{x}$ & & & $\mathrm{x}$ \\
\hline & Campylocentrum burchellii Cogn. & HLO & $\mathrm{X}$ & $\mathrm{X}$ & $\mathrm{x}$ & $\mathrm{x}$ \\
\hline & Capanemia australis (Kraenzl.) Schltr. & HLO & $\mathrm{x}$ & $\mathrm{x}$ & $\mathrm{x}$ & $\mathrm{x}$ \\
\hline & Capanemia superflua (Rchb. f.) Garay & HLO & & $\mathrm{X}$ & $\mathrm{x}$ & $\mathrm{x}$ \\
\hline & Capanemia thereziae Barb. Rodr. & HLO & $\mathrm{x}$ & & & $\mathrm{x}$ \\
\hline & Cryptophoranthus langeanus (Kraenzl.) Garay & HLO & $\mathrm{x}$ & $\mathrm{x}$ & & $\mathrm{x}$ \\
\hline & Cyclopogon trifasciatus Schltr. & HLF & $\mathrm{x}$ & & & \\
\hline & Dryadella liliputiana (Cogn.) Luer & HLO & $\mathrm{x}$ & & & \\
\hline & Epidendrum caldense Barb. Rodr. & HLO & $\mathrm{x}$ & & & \\
\hline & Eurystyles cotyledon Wawra & HLO & & & & $\mathrm{x}$ \\
\hline & Gomesa recurva Lodd. & HLO & $\mathrm{x}$ & $\mathrm{x}$ & $\mathrm{x}$ & \\
\hline & Isabelia pulchella (Kraenzl.) Senghas e Teusch. & HLO & $\mathrm{x}$ & & $\mathrm{x}$ & \\
\hline & Leptotes unicolor Barb. Rodr. & HLO & $\mathrm{X}$ & & & $\mathrm{x}$ \\
\hline & Lophiaris pumila (Lindl.) Braem & HLO & $\mathrm{X}$ & $\mathrm{x}$ & $\mathrm{x}$ & $\mathrm{x}$ \\
\hline & Maxillaria juergensii Schltr. & HLO & $\mathrm{X}$ & $\mathrm{x}$ & $\mathrm{x}$ & \\
\hline & Maxillaria picta Hook. & HLO & $\mathrm{x}$ & & & $\mathrm{x}$ \\
\hline & Octomeria elobata Schltr. & HLO & $\mathrm{x}$ & & & \\
\hline & Octomeria palmyrabellae Barb. Rodr. & HLO & $\mathrm{x}$ & & & \\
\hline & Oncidium fimbriatum Hoffmanns. & HLO & $\mathrm{x}$ & & & \\
\hline & Oncidium longicornu Mutel & HLO & $\mathrm{x}$ & & $\mathrm{x}$ & $\mathrm{x}$ \\
\hline & Oncidium longipes Lindl. & HLO & $\mathrm{x}$ & & & \\
\hline & Oncidium paranaense Kraenzl. & HLO & & & & \\
\hline & Oncidium raniferum Lindl. & HLO & $\mathrm{x}$ & $\mathrm{X}$ & $\mathrm{x}$ & $\mathrm{x}$ \\
\hline & Pleurothallis adenochila Loef. & HLO & $\mathrm{X}$ & & $\mathrm{x}$ & \\
\hline & Pleurothallis aveniformis Hoehne & HLO & & & & $\mathrm{x}$ \\
\hline & Pleurothallis bradei Schltr. & HLO & $\mathrm{X}$ & $\mathrm{x}$ & $\mathrm{x}$ & \\
\hline & Pleurothallis crepiniana Cogn. & HLO & & & & $\mathrm{x}$ \\
\hline & Pleurothallis dryadum Schltr. & HLO & $\mathrm{x}$ & $\mathrm{x}$ & & \\
\hline & Pleurothallis grobyi Bateman ex Lindl. & HLO & $\mathrm{X}$ & & & $\mathrm{x}$ \\
\hline & Pleurothallis hatschbachii Schltr. & HLO & & & $\mathrm{x}$ & $\mathrm{x}$ \\
\hline & Pleurothallis hygrophila Barb. Rodr. & HLO & $\mathrm{X}$ & & $\mathrm{x}$ & $\mathrm{x}$ \\
\hline & Pleurothallis loranthophylla Rchb. f. & HLO & $\mathrm{x}$ & $\mathrm{x}$ & $\mathrm{x}$ & \\
\hline & Pleurothallis luteola Lindl. & HLO & $\mathrm{x}$ & & & $\mathrm{x}$ \\
\hline & Pleurothallis marginalis Rchb. f. & HLO & $\mathrm{x}$ & & & $\mathrm{x}$ \\
\hline & Pleurothallis mattinensis Hoehne & HLO & $\mathrm{x}$ & & $\mathrm{x}$ & \\
\hline & Pleurothallis mentigera Kraenzl. & HLO & $\mathrm{x}$ & & & \\
\hline & Pleurothallis mirabilis Schltr. & HLO & $\mathrm{x}$ & & & \\
\hline & Pleurothallis mouraeoides Hoehne & HLO & $\mathrm{x}$ & & & $\mathrm{x}$ \\
\hline & Pleurothallis paranaensis Schltr. & HLO & $\mathrm{x}$ & $\mathrm{x}$ & & \\
\hline & Pleurothallis pruinosa Barb. Rodr. & HLO & $\mathrm{x}$ & & & $\mathrm{x}$ \\
\hline & Pleurothallis sarracenia Luer & HLO & $\mathrm{x}$ & & & \\
\hline & Pleurothallis saurocephala Lodd. & HLO & & & & \\
\hline & Pleurothallis sonderana Rchb. f. & HLO & $\mathrm{x}$ & & $\mathrm{x}$ & $\mathrm{x}$ \\
\hline & Prosthechea fausta (Rchb. f.) W. E. Higgins & HLO & $\mathrm{x}$ & $\mathrm{x}$ & $\mathrm{x}$ & \\
\hline & Stelis porschiana Schltr. & HLO & $\mathrm{x}$ & & & \\
\hline & Zygostates alleniana Kraenzl. & HLO & $\mathrm{X}$ & & & \\
\hline \multirow[t]{4}{*}{ PIPERACEAE (4) } & Peperomia catharinae Miq. & HLO & $\mathrm{X}$ & & & $\mathrm{x}$ \\
\hline & Peperomia caulibarbis Miq. & HLP & $\mathrm{x}$ & $\mathrm{x}$ & $\mathrm{x}$ & $\mathrm{x}$ \\
\hline & Peperomia tetraphylla (G. Forst.) Hook. e Arn. & HLO & $\mathrm{x}$ & & & $\mathrm{x}$ \\
\hline & Peperomia trineura Miq. & HLO & $\mathrm{x}$ & $\mathrm{x}$ & $\mathrm{x}$ & $\mathrm{x}$ \\
\hline \multirow[t]{4}{*}{ POLYPODIACEAE (15) } & Campyloneurum acrocarpon Fée & HLP & $\mathrm{x}$ & & & $\mathrm{x}$ \\
\hline & Campyloneurum austrobrasilianum (Alston) de la Sota & HLO & $\mathrm{X}$ & & & $\mathrm{x}$ \\
\hline & Campyloneurum nitidum (Kaulf.) C. Presl & HLP & $\mathrm{x}$ & $\mathrm{x}$ & $\mathrm{x}$ & $\mathrm{x}$ \\
\hline & Lellingeria schenckii (Hieron.) A. R. Sm. e R. C. Moran & HLO & $\mathrm{x}$ & $\mathrm{x}$ & $\mathrm{x}$ & $\mathrm{x}$ \\
\hline
\end{tabular}

FLORESTA, Curitiba, PR, v. 39, n. 1, p. 51-66, jan./mar. 2009. 


\begin{tabular}{|c|c|c|c|c|c|c|}
\hline & Microgramma squamulosa (Kaulf.) de la Sota & HLO & $\mathrm{x}$ & & & $\mathrm{x}$ \\
\hline & Niphidium crassifolium (L.) Lellinger & HLO & $\mathrm{x}$ & $\mathrm{X}$ & $\mathrm{x}$ & \\
\hline & Pecluma pectinatiformis (Lindl.) M. G. Price & HLO & $\mathrm{x}$ & & & $\mathrm{x}$ \\
\hline & Pecluma recurvata (Kaulf.) M. G. Price & HLO & $\mathrm{x}$ & $\mathrm{x}$ & & \\
\hline & Pecluma sicca (Lindm.) M. G. Price & HLO & $\mathrm{x}$ & & & $\mathrm{x}$ \\
\hline & Pecluma singeri (de la Sota) M. G. Price & HLO & $\mathrm{x}$ & $\mathrm{x}$ & $\mathrm{x}$ & $\mathrm{x}$ \\
\hline & Pleopeltis pleopeltifolia (Raddi) Alston & HLO & $\mathrm{x}$ & & & $\mathrm{x}$ \\
\hline & Pleopeltis macrocarpa (Willd.) Kaulf. & HLO & $\mathrm{x}$ & $\mathrm{x}$ & $\mathrm{x}$ & $\mathrm{x}$ \\
\hline & Polypodium catharinae Langsd. e Fisch. & HLO & $\mathrm{x}$ & $\mathrm{x}$ & $\mathrm{x}$ & $\mathrm{x}$ \\
\hline & Polypodium hirsutissimum Raddi & HLO & $\mathrm{x}$ & $\mathrm{x}$ & $\mathrm{x}$ & $\mathrm{x}$ \\
\hline & Polypodium pleopeltidis Fée & HLO & $\mathrm{x}$ & $\mathrm{x}$ & $\mathrm{x}$ & $\mathrm{x}$ \\
\hline \multirow[t]{2}{*}{ PTERIDACEAE (2) } & Doryopteris nobilis (Moore) C. Chr. & HLA & & & & $\mathrm{x}$ \\
\hline & Vittaria lineata (L.) Sm. & HLO & $\mathrm{x}$ & & & $\mathrm{x}$ \\
\hline \multirow[t]{2}{*}{ THELYPTERIDACEAE (2) } & Thelypteris araucariensis Ponce & HLA & $\mathrm{x}$ & & & \\
\hline & Thelypteris decusata (L.) Proctor & HLA & $\mathrm{x}$ & & & \\
\hline THYMELAEACEAE (1) & Daphnopsis racemosa Griseb. & HLA & & & & \\
\hline WOODZIACEAE (1) & Deparia petersenii (Kunze) M. Kato & HLA & & & & $\mathrm{x}$ \\
\hline Total & & & 91 & 43 & 50 & 72 \\
\hline
\end{tabular}

A riqueza florística variou de 29 espécies na estação de Campina a 83 espécies em Contenda. Além dessas, Pinhais apresentou 48 espécies, Barigui 58 espécies, Araucária 64, Guajuvira 44, General Lúcio 36 e Balsa Nova 34. Excluindo-se os dois extremos, a média por estação foi de 45 espécies. Nas florestas de planície, foram registradas 81 espécies; nas de encosta, 91. Do total, 58 espécies ocorreram em apenas um dos compartimentos e 56 em ambos, sendo 25 nas planícies e 33 nas encostas. Um total de 20 espécies foi observado em pelo menos sete localidades. Considerando-se apenas as florestas de planície, 22 espécies ocorreram em todas as seis estações e 24 em ao menos cinco. No outro extremo, 52 espécies foram observadas em apenas uma ou duas localidades. Nas florestas em estágio inicial de regeneração, foram observadas 43 espécies, enquanto nas florestas em estágio médio de regeneração foram observadas 72 espécies.

A maioria das estações contribui pouco para a riqueza florística. Considerando apenas as estações amostrais Araucária e Contenda, a riqueza foi igual a 97 espécies; as cinco localidades restantes contribuíram com 17 espécies. Duas estações (Campina e Gen. Lúcio) não contribuíram com nenhuma espécie exclusiva. Considerando-se apenas as planícies, 90\% das espécies foram registradas nas duas localidades mais ricas (Araucária e Barigui). $\mathrm{O}$ índice de diversidade $\beta$ de Harrison $\left(\beta_{H I}\right)$ foi calculado em 0,18 .

Predominaram holoepífitas características com 98 espécies (86\%). As epífitas acidentais contribuíram com sete espécies, e as facultativas e as hemiepífitas com apenas três espécies cada.

A semelhança entre as estações estudadas no Primeiro Planalto Paranaense pode ser observada na tabela 3 e na figura 1. Guajuvira foi, na média, mais semelhante às demais áreas. Dois grandes grupos se formaram, um composto por Pinhais, Contenda, Barigui e Araucária, e outro pelas demais áreas.

Tabela 3. Similaridade florística (índice de Jaccard) entre as estações levantadas no Primeiro Planalto Paranaense (marcados em negrito os maiores valores).

Table 3. Jaccard similarity index among the study sites in the Curitiba plateau, higher values are on bold.

\begin{tabular}{lccccccc}
\hline LOCAL & Pinhais & Contenda & Barigui & Araucária & Campina & Guajuvira & Gen Lúcio \\
\hline Contenda & 0,44 & & & & & & \\
Barigui & 0,39 & 0,47 & & & & & \\
Araucária & 0,44 & 0,48 & $\mathbf{0 , 6 7}$ & & & & \\
Campina & 0,31 & 0,26 & 0,43 & 0,43 & & & \\
Guajuvira & 0,37 & 0,31 & 0,55 & 0,57 & $\mathbf{0 , 5 9}$ & & \\
Gen. Lucio & 0,38 & 0,31 & 0,47 & 0,47 & 0,44 & 0,57 & \\
B. Nova & 0,34 & 0,27 & 0,44 & 0,44 & 0,50 & 0,50 & $\mathbf{0 , 5 9}$ \\
\hline
\end{tabular}




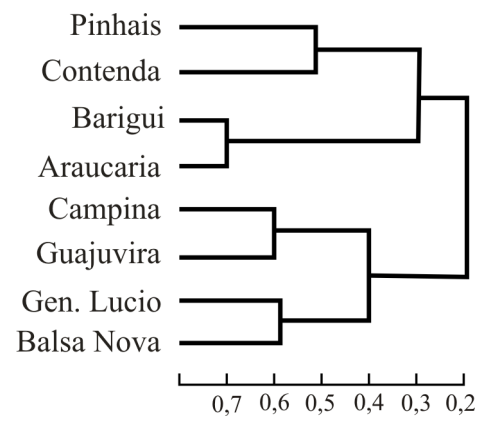

Figura 1. Dendrograma de similaridade entre as estações analisadas, baseado no índice de Jaccard. Figure 1. Similarity dendrogram based on Jaccard index among the study sites.

Dentre os estudos realizados no Brasil, aqueles com maior semelhança florística ao planalto estudado foram Borgo; Silva (2003) e Dittrich et al. (1999), com IJ = 0,45, ambos no município de Curitiba, vizinho à área deste estudo. Excluindo-se os localizados na bacia do alto Iguaçu, assemelham-se Kersten et al. (no prelo) na região de Guarapuava (IJ $=0,45$ ), na bacia do médio Iguaçu. Afora eles, destaca-se o trabalho de Giongo; Waechter (2004) na região da depressão central do Rio Grande do Sul $(\mathrm{IJ}=0,20)$. Os demais trabalhos realizados no estado do Paraná (SCHUTZ-GATTI, 2000; KERSTEN; SILVA, 2001; BORGO et al., 2002; KERSTEN; SILVA, 2006) obtiveram índice de similaridade inferior a $10 \%$.

Nos estudos quantitativos, foram registradas 42 espécies de epífitos vasculares, correspondendo a $40 \%$ das espécies observadas na região e $60 \%$ das espécies registradas nas estações em que o estudo foi realizado. $80 \%$ das observações receberam nota de dominância $1,12 \%$ nota 2 e apenas $8 \%$ nota 3 . A suficiência amostral foi atingida com 35 forófitos no estágio inicial e com 40 forófitos no estágio médio (Figura 2). As 10 principais espécies somam $82 \%$ do VIE no estágio inicial e $75 \%$ no estágio médio. O percentual de $95 \%$ do VIE é atingido com as 18 principais espécies no estágio inicial e com 24 espécies no médio. No estágio inicial apenas 19 espécies foram registradas em mais de 5\% dos forófitos, enquanto no estágio médio, 29 espécies ocorreram em mais de 5\% dos forófitos.

A dominância total no estágio inicial foi igual a 377, enquanto no estágio médio foi igual a 732. Os índices de diversidade calculados para os dois estágios serais podem ser observados na tabela 5. O teste de Kolmogorov-Smirnov mostrou que as duas comunidades são diferentes tanto na análise da frequência forofítica $\left(D_{\max }=0,1571, P=0,449\right)$ quanto na análise dos valores de importância $\left(D_{\max }=0,1280\right.$, $\mathrm{P}=0,710$ ).

Em ambas as formações, duas espécies destacaram-se como importantes (Tabela 4), com valor de importância bem superior ao das demais. Microgramma squamulosa e Pleopeltis pleopeltifolia foram registradas em mais de 50\% das zonas e $75 \%$ dos forófitos, apenas alternando-se como mais importantes, no entanto as comunidades foram bem diferenciadas entre os estágios sucessionais (Tabela 4). Destacamse duas famílias, Polypodiaceae e Orchidaceae, que somam, nos dois casos, mais de $70 \%$ do VIE.

O número de espécies epífitas nos forófitos amostrados variou de 2 a 12 nas florestas em estágio inicial e de 3 a 17, naquelas em estágio médio, sendo o número máximo registrado sobre um indivíduo de Erythrina crista-galli (corticeira). Em ambos os estágios são observados diversos indivíduos sem epífitas ou com apenas uma espécie, principalmente sobre a espécie arbórea dominante (Sebastiania commersoniana).

Embora todas as estações levantadas tenham sido classificadas como em estágio inicial ou médio de regeneração, certas áreas das estações Araucária e Barigui aparentavam estar mais bem desenvolvidas no processo de regeneração.

Baseando-se nas estimativas de abundância e distribuição das espécies nas diferentes estações de floresta de planície amostradas, assim como em observações de campo, foi possível estabelecer três grupos sucessionais de espécies: pioneiras, secundárias e avançadas (Tabela 6). Não foram definidas espécies clímax por causa do pouco conhecimento sobre florestas bem conservadas. As espécies pioneiras assim como as avançadas foram subdivididas em iniciais e tardias. 
Tabela 4. Principais espécies (95\% do VIE) amostradas nos estágios inicial e médio das florestas ribeirinhas do Primeiro Planalto Paranaense, em ordem decrescente de valor de importância da floresta em estágio médio, com os respectivos parâmetros fitossociológicos (FfA = frequência absoluta nos forófitos, DoA= dominância absoluta, VIE = valor de importância epifítico, Ord. = Ordenação por valor de importância das espécies na formação inicial, Var. indica alteração na importância das espécies do estágio inicial para o médio, para mais $(\uparrow)$, menos $(\downarrow)$ ou estabilidade (=).

Table 4. Main species (95\% of VIE) sample on the river plain early and mid-succession forest seres, ranked by mid-succession VIE (FfA $=$ absolute frequency on the host tree, DoA $=$ absolute dominance, VIE = epiphyte importance value, Ord. = mid-sucession VIE rank., Var. = VIE change patter from early to mid sucession forest: $\uparrow$ - upward,$\downarrow-$ downward or - $=-$ stability).

\begin{tabular}{|c|c|c|c|c|c|c|c|c|c|}
\hline & \multirow{2}{*}{ Espécie } & \multicolumn{4}{|c|}{ Inicial } & \multicolumn{3}{|c|}{ Médio } & \multirow[b]{2}{*}{ Var. } \\
\hline & & $\operatorname{FfA}(\%)$ & DoA & VIE & Ord. & $\operatorname{FfA}(\%)$ & DoA & VIE2 & \\
\hline 1 & Microgramma squamulosa & 64 & 62 & 14,4 & 2 & 98 & 176 & 18,1 & $\uparrow$ \\
\hline 2 & Pleopeltis pleopeltifolia & 98 & 131 & 26,8 & 1 & 100 & 122 & 14,6 & $\downarrow$ \\
\hline 3 & Polypodium hirsutissimum & 60 & 38 & 10,8 & 4 & 76 & 54 & 8,4 & $\uparrow$ \\
\hline 4 & Peperomia catharinae & 42 & 31 & 8,1 & 6 & 62 & 60 & 8,0 & $\uparrow$ \\
\hline 5 & Capanemia australis & 78 & 43 & 13,2 & 3 & 62 & 39 & 6,5 & $\downarrow$ \\
\hline 6 & Lepismium lumbricoides & 4 & 3 & 0,8 & 16 & 38 & 33 & 4,6 & $\uparrow$ \\
\hline 7 & Pleurothallis aveniformis & 8 & 5 & 1,4 & 13 & 44 & 25 & 4,4 & $\uparrow$ \\
\hline 8 & Aechmea distichantha & 8 & 5 & 1,4 & 14 & 26 & 35 & 4,0 & $\uparrow$ \\
\hline 9 & Campyloneurum austrobrasilianum & 16 & 8 & 2,6 & 9 & 34 & 23 & 3,7 & $\uparrow$ \\
\hline 10 & Campylocentrum burchellii & 64 & 33 & 10,5 & 5 & 30 & 16 & 3,0 & $\downarrow$ \\
\hline 11 & Pleurothallis hygrophila & 6 & 3 & 1,0 & 15 & 26 & 20 & 3,0 & $\uparrow$ \\
\hline 12 & Lepismium houlletianum & 20 & 11 & 3,4 & 8 & 20 & 18 & 2,5 & $\downarrow$ \\
\hline 13 & Tillandsia stricta & 22 & 12 & 3,7 & 7 & 22 & 13 & 2,3 & $\downarrow$ \\
\hline 14 & Oncidium spp. & - & - & - & - & 22 & 14 & 2,3 & $\uparrow$ \\
\hline 15 & Tillandsia tenuifolia & 14 & 8 & 2,4 & 10 & 18 & 9 & 1,7 & $\downarrow$ \\
\hline 16 & Vriesea reitzii & 2 & 2 & 0,5 & 17 & 10 & 9 & 1,2 & $\uparrow$ \\
\hline 17 & Pleurothallis sonderana & - & - & - & - & 12 & 6 & 1,2 & $\uparrow$ \\
\hline 18 & Pecluma sicca & 12 & 9 & 2,3 & 11 & 10 & 6 & 1,0 & $\downarrow$ \\
\hline 19 & Campylocentrum aromaticum & 12 & 6 & 1,9 & 12 & 8 & 5 & 0,8 & $\downarrow$ \\
\hline 20 & Campyloneurum nitidum & - & - & - & - & 8 & 5 & 0,8 & $=$ \\
\hline 21 & Asplenium gastonis & - & - & - & - & 8 & 4 & 0,8 & $\uparrow$ \\
\hline 22 & Leptotes unicolor & - & - & - & - & 8 & 4 & 0,8 & $\uparrow$ \\
\hline 23 & Trichomanes pyxidiferum & - & - & - & - & 8 & 4 & 0,8 & $\uparrow$ \\
\hline & Total & & 509 & & & & 732 & & \\
\hline
\end{tabular}

Tabela 5. Índices de diversidade $\alpha$ calculados para os dois estágios serais considerados e $\beta$ para a florística.

Table 5. Diversity and species richness indices estiamated for the considered sucessional seres.

\begin{tabular}{lcc}
\hline Índice & Inicial & Médio \\
\hline Margalef $\left(\mathrm{D}_{\mathrm{Mg}}\right)$ & 3,91 & 5,47 \\
Jaccard $\left(\mathrm{H}^{\prime}\right)$ & 2,60 & 3,04 \\
Equidade $\left(\mathrm{J}^{\prime}\right)$ & 0,74 & 0,84 \\
McIntosh $(\mathrm{D})$ & 0,73 & 0,78 \\
Simpson $(\mathrm{D})$ & 0,84 & 0,94 \\
\hline
\end{tabular}




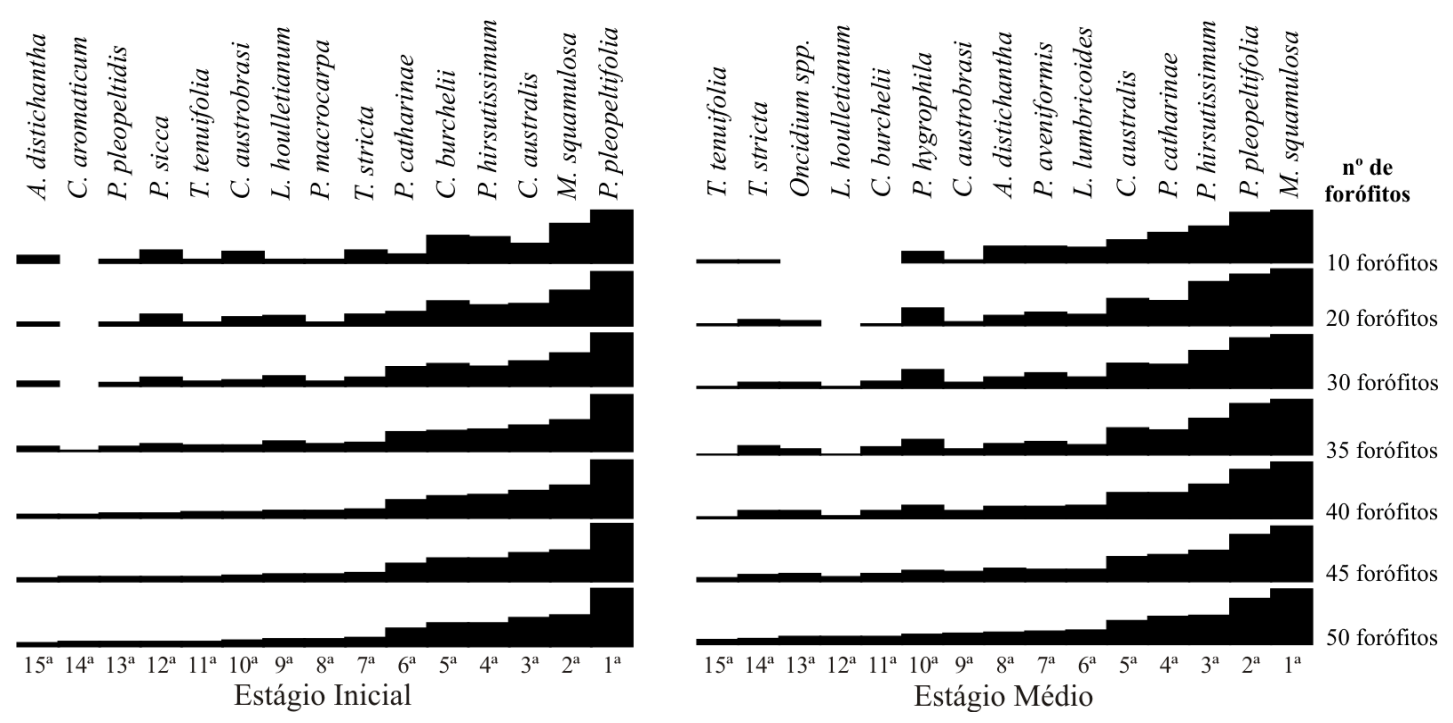

Figura 2. Avaliação da suficiência amostral das florestas do Primeiro Planalto Paranaense - valor de importância das 15 principais espécies, considerando-se diferentes números de forófitos.

Figure 2. Sampling accuracy: change in the importance order of the 15 main species with varying host tree number.

Tabela 6. Grupos sucessionais de espécies epifíticas nas florestas de planície do primeiro planalto paranaense, ordenadas alfabeticamente. As espécies pioneiras e as avançadas estão subdivididas.

Table 6. Species typical of tree succession seres on the river plain forests of the Curitiba plateau, alphabetically ordered. The early-succession (Pioneiras) and Late-succession (Avançadas) species are subdivided.

\begin{tabular}{|c|c|c|c|c|}
\hline & Pioneiras & Secundárias & & Avançadas \\
\hline \multirow{9}{*}{ 苞 } & Capanemia australis & Aechmea recurvata & & Cryptophoranthus langeanus \\
\hline & Campylocentrum aromaticum & Asplenium gastonis & & Gomesa recurva \\
\hline & Campylocentrum burchellii & Campyloneurum nitidum & & Hymenophyllum polyanthos \\
\hline & Campyloneurum austrobrasilianum & Hatiora salicornioides & & Maxillaria picta \\
\hline & Lepismium houlletianum & Lepismium lumbricoides & & Oncidium longicornu \\
\hline & Leptotes unicolor & Lophiaris pumila & & Philodendron loefgrenii \\
\hline & Microgramma squamulosa & Oncidium fimbriatum & & Pleurothallis grobyi \\
\hline & Pleopeltis pleopeltifolia & Oncidium raniferum & 㐘 & Pleurothallis hatschbachii \\
\hline & Polypodium hirsutissimum & Pecluma pectinatiformis &.$\Xi$ & Pleurothallis luteola \\
\hline \multirow{12}{*}{ : } & Tillandsia stricta & $\begin{array}{l}\text { Pecluma sicca } \\
\text { Pleopeltis macrocarpa }\end{array}$ & & $\begin{array}{l}\text { Pleurothallis marginalis } \\
\text { Pleurothallis mouraeoides }\end{array}$ \\
\hline & Aechmea distichantha & Pleurothallis hatschbachii & & Rhipsalis floccosa \\
\hline & Eurystyles cotyledon & Pleurothallis hygrophila & & Rhipsalis neves-armondii \\
\hline & Lepismium lumbricoides & Polypodium pleopeltidis & & Rumohra adiantiformis \\
\hline & Peperomia catharinae & Rhipsalis teres & & Sinningia douglasii \\
\hline & Peperomia tetraphylla & Vittaria lineata & \multirow{7}{*}{ : } & \\
\hline & Pleurothallis aveniformis & Vriesea friburgensis & & \\
\hline & Pleurothallis sonderana & Vriesea reitzii & & Asplenium incurvatum \\
\hline & Polypodium catharinae & Trichomanes pyxidiferum & & Barbosella australis \\
\hline & Tillandsia recurvata & & & Billbergia nutans \\
\hline & Tillandsia tenuifolia & & & Vriesea philippocoburgi \\
\hline & Tillandsia usneoides & & & Vriesea platynema \\
\hline
\end{tabular}




\section{DISCUSSÃO}

A presença de duas espécies exóticas é indicativa de perturbações nos ambientes em questão. Apesar de registradas em percentual inferior ao de Borgo; Silva (2003), em que mais de 10\% das espécies não pertenciam ao ambiente, as registradas neste estudo podem ser consideradas contaminantes biológicos no ambiente epifítico. Impatiens walleriana, cultivada como ornamental, com frequência bastante elevada é registrada como terrícola em regiões silvestres ou crescendo em fendas de calçadas e paredes. Qualquer mínima concentração de água, aparentemente, permite seu crescimento. Ligustrum lucidum, arbórea, normalmente terrícola, nunca havia sido registrada no ambiente epífito. Medindo quase cinco metros de altura e com perímetro na base maior que $40 \mathrm{~cm}$, foi observada sobre uma Erythrina crista-galli (corticeira) e sobreviveu mais de um ano após a queda do galho em que estava assentada. Suas sementes suculentas são atrativo apetitoso para aves nativas, que acabam por disseminar essa espécie mesmo dentro das florestas. A casca do forófito que a sustenta, espessa e descamante, facilmente acumulando água, assim como o porte e a disposição horizontal dos galhos, contribuíram para o estabelecimento e desenvolvimento desse indivíduo.

Dentre as espécies registradas em ao menos sete estações, algumas são de ampla distribuição, sendo registradas em todas as formações das florestas paranaenses. Outras são de distribuição mais restrita, ocorrendo apenas em determinadas florestas. Estas podem ser consideradas características das florestas do Primeiro Planalto Paranaense. Das 20 espécies observadas em ao menos sete localidades, seis ocorrem em todas as florestas paranaenses amostradas até o momento (Tillandsia stricta, Tillandsia tenuifolia, Campyloneurum nitidum, Pleopeltis pleopeltifolia, Polypodium hirsutissimum e Polypodium catharinae), seis são também observadas nas florestas estacionais brasileiras (Leptotes unicolor, Pecluma sicca, Aechmea distichantha, Tillandsia usneoides, Pleurothallis sonderana e Microgramma squamulosa), duas ocorrem em Floresta Ombrófila Densa (Lepismium houlletianum e Vittaria lineata) e três são registradas em florestas sobre restingas (Lepismium lumbricoides, Pleurothallis hygrophila e Peperomia catharinae). As três restantes (Campylocentrum burchellii, Capanemia australis e Campyloneurum austrobrasilianum), apesar de abundantes nas planícies do primeiro planalto paranaense, não foram ainda citadas para outras florestas brasileiras. Sua associação com Peperomia catharinae, Pleurothallis hygrophila e Leptotes unicolor e com as espécies mais comuns (M. squamulosa e $P$. pleopeltifolia) pode ser considerada diagnóstica da Floresta Ombrófila Mista paranaense, não tendo sido, até o momento, registrada para nenhuma outra floresta brasileira. Analogamente, Vriesea reitzii e Pleurothallis aveniformis separam as florestas de planícies, onde são abundantes, das de encosta.

A riqueza florística pode ser considerada elevada, principalmente por serem as estações, em sua maioria, florestas jovens. $\mathrm{O}$ trabalho em floresta com araucária foi o que apresentou maior riqueza específica, tendo registrado mais espécies que nas 14 estações (97 ha) inventariadas por Borgo e Silva (2003). Em conjunto e descontadas as espécies alóctones, os trabalhos publicados para e região (CERVI; DOMBROWISKI, 1985; CERVI et al., 1988; DITTRICH et al., 1999; KERSTEN; SILVA, 2002; BORGO; SILVA, 2003) registram cerca de 115 espécies, três a mais que o presente estudo.

Mesmo quando comparada com localidades mais desenvolvidas ou ecossistemas com epífitas mais abundantes, a riqueza florística é elevada. Apresenta mais espécies do que as encontradas no Morro Facãozinho (Pico Marumbi) (PETEAN, 2003), em duas localidades da Ilha do Mel (KERSTEN; SILVA, 2001; 2006), em Torres (RS) (WAECHTER, 1992) e em algumas localidades do Rio Grande do Sul (WAECHTER, 1992; GONÇALVES; WAECHTER, 2002; ROGALSKI; ZANNIN, 2003; GIONGO; WAECHTER, 2004).

Não se pode, no entanto, atribuir a riqueza florística à diversidade beta (entre os pontos), pois muitas das estações não contribuíram ou contribuíram pouco com o número final de espécies. $\mathrm{Na}$ diversidade de Harrison, que varia de $0-1$ e mede o acréscimo (turnover) de espécies entre localidades (zero correspondendo a sítios com a mesma flora e um à ausência de sobreposição florística), embora não haja base para comparação, pode-se afirmar que o valor foi baixo, o que pode ser explicado pelo fato de apenas algumas áreas concentrarem grande parte da riqueza e a maioria contribuir muito pouco para a florística. Além disto, a maior parte das espécies apresentou frequência muito baixa. Considerando as espécies registradas em 5\% ou menos dos forófitos adicionadas às não-amostradas nos estudos quantitativos, $70 \%$ podem ser consideradas raras. Assim, talvez o epifitismo mais conspícuo atualmente observado na Floresta Ombrófila Densa (KERSTEN, 2006) resulte apenas do atual estado de conservação 
da Floresta com Araucária, praticamente extinta no estado (CASTELA; BRITEZ, 2004).

Áreas ao longo de rios de planalto estão condicionadas à sua dinâmica. São, em geral, criadas pela movimentação do curso d'água na planície, curvas de degradação e de agradação. Quando localizadas em curvas de degradação, sobre solos mais antigos, as florestas regularmente apresentam idade mais avançada e riqueza do componente arbóreo mais elevada. Quando localizadas em curvas de agradação e, portanto, sobre solos recentemente depositados, são florestas mais jovens, formadas essencialmente por branquilho (Sebastiania commersoniana) (CURCIO, 2006). As estações do primeiro planalto enquadram-se ora em uma, ora em outra dessas situações. As estações Barigui e Araucária, assentadas sobre superfícies de degradação, apresentam-se em estádio mais avançado de desenvolvimento, estando, não obstante, alteradas pela retirada das principais espécies madeireiras. Muito poucos indivíduos de Lauraceae são registrados, e as maiores árvores raramente ultrapassam $80 \mathrm{~cm}$ de PAP (perímetro à altura do peito). As estações de Campina, General Lúcio e Balsa Nova, por sua vez, enquadram-se na segunda situação, o que, associado à intensa pressão do homem sobre esses ambientes, explicaria sua baixa riqueza florística.

$\mathrm{Na}$ análise de grupamento (Figura 1), formaram-se dois grupos distintos entre as estações, um composto por estações mais jovens e com menor riqueza (Campina, Guajuvira, General Lúcio e Balsa Nova) e outro pelas mais desenvolvidas (Pinhais, Contenda, Barigui e Araucária). Nesse segundo grupo, separam-se as florestas de planícies das florestas de encosta, mostrando que tanto a proximidade ao rio quanto o grau de desenvolvimento das formações influencia a composição florística das comunidades. Assim como em Kersten et al. (no prelo), esses dois ambientes apresentaram flora distinta. A explicação para isso, neste caso, é relativa principalmente à idade das florestas, mais conservadas nas encostas que nas margens de rios.

A estrutura das comunidades, assim como a composição florística, foi diferenciada entre os estágios sucessionais das florestas ribeirinhas. As florestas em estágio médio obtiveram dominância total $66 \%$ maior, além de apresentarem valores mais elevados em todos os índices de diversidade. A maior dominância total reflete tanto um maior número de indivíduos/grupamentos como maiores notas atribuídas às espécies. Assim, ao se caminhar pela floresta em estágio médio de regeneração, serão observados tanto mais indivíduos como indivíduos maiores.

Os diferentes índices de diversidade refletem diferentes situações. O índice florístico de Margalef é uma relação entre o número de espécies e o de indivíduos em uma comunidade. Reflete, de certa forma, a probabilidade de não se encontrar duas vezes a mesma espécie. As florestas em estágio médio apresentam esse índice 40\% superior ao das florestas iniciais. Os índices de McIntosh e Simpson variam entre $0-1$. Simpson avalia a probabilidade de dois indivíduos escolhidos ao acaso na comunidade pertencerem à mesma espécie (MAGURRAN, 2004). Ainda, os tradicionais índices de Shannon e a equidade calculam a relação entre a proporção dos indivíduos de cada espécie. Comunidades com poucas espécies muito dominantes apresentam menor índice, e quanto mais semelhante for o número de indivíduos de diferentes espécies maior será o índice. O aumento de seu valor da floresta em estágio inicial para a em estágio médio mostra que, na primeira, menos espécies representam a maioria dos indivíduos, e que na floresta em estágio médio, maior número de espécies aparece em proporção mais significativa na comunidade.

Dentre os índices considerados, o de Shannon é o único amplamente utilizado e pode servir para comparação com outras áreas. Nos dois estágios considerados, os valores foram relativamente baixos, maior apenas que nos trabalhos de Taim e Osório, no Rio Grande do Sul (WAECHTER, 1992; 1998), sob clima estacional, e no levantamento de Guarapuava (KERSTEN et al., no prelo), localizada na região mais fria do estado. Mesmo trabalhos em florestas meridionais do interior (GIONGO; WAECHTER, 2004) ou litoral (WAECHTER, 1992 - Torres; GONÇALVES; WAECHTER, 2002 - Terra de Areia), apresentaram valores maiores. Embora a ocorrência de poucas espécies com grandes valores de importância e de muitas com valores baixos também tenha sido registrada em outros levantamentos (WAECHTER, 1992; 1998; KERSTEN; SILVA, 2001; GONÇALVES; WAECHTER, 2002), em nenhum outro as duas primeiras ficaram tão isoladas como neste, como demonstrado pela baixa diversidade (H'). Considera-se isso indicativo de ambiente em processo inicial de sucessão ou muito alterado pela ação humana.

Dentre as duas principais espécies, em ambas as seres, foram registradas principalmente as poiquilohidricas, notadamente as polipodiáceas, com destaque para Pleopeltis pleopeltifolia e 
Microgramma squamulosa. A primeira destaca-se por sua elevada frequência e ocorre, geralmente, em pequenas touceiras, raramente conspícuas à primeira vista. Já a segunda frequentemente ocupa grandes porções dos galhos ou mesmo a copa por inteiro. Essas espécies são comuns em árvores da arborização urbana de diversas cidades do Paraná (observação pessoal), indicando sua capacidade de colonização de novos ambientes. As espécies que mais aumentaram de importância do estágio inicial para o médio (Lepismium lumbricoides, Pleurothallis aveniformis, Aechmea distichantha e Pleurothallis hygrophila) foram todas ainda consideradas pioneiras no ambiente epifítico, mas são, no entanto, bem menos comuns em árvores isoladas ou na arborização urbana. Aparentemente, a estrutura das florestas reafirma o observado por Wolf (2005), que diz que distúrbios antropogênicos forçam uma mudança de espécies mésicas para espécies poiquiloídricas, amplamente dominantes nesses ambientes.

É interessante notar a pouca importância das Bromeliaceae. Essa família destacou-se em quase todos os trabalhos quantitativos no Brasil (WAECHTER, 1992; 1998; SCHUTZ-GATTI, 2000; KERSTEN; SILVA, 2001; 2005; GONÇALVES; WAECHTER, 2002; GIONGO;WAECHTER, 2004), seja pela importância de Tillandsia nas regiões mais setentrionais (WAECHTER, 1992; 1998; GONÇALVES; WAECHTER, 2002), seja de Vriesea nas zonas mais tropicais (SCHUTZ-GATTI, 2000; KERSTEN; SILVA, 2005). Neste estudo, nenhum dos dois gêneros foi considerado importante. A única bromélia entre as dez mais importantes foi $A$. distichanta. Novamente, isso parece indicar ambiente em fase inicial de sucessão, intensas alterações humanas ou um combinado das duas causas.

A preferência pela copa é fenômeno consagrado para a flora epifítica, tendo sido registrada para a maioria dos trabalhos publicados no Brasil (WAECHTER, 1992; KERSTEN; SILVA, 2001; GONÇALVES; WAECHTER, 2002; GIONGO;WAECHTER, 2004), assim como no exterior (JOHANSSON, 1974; SUGDEN; ROBINS, 1979; INGRAM; NADKARNI, 1993; FREIBERG, 1996). Nieder et al. (2001) afirmaram, quanto à ocorrência de epífitas em zonas do forófito, que próximo à superfície externa das copas é observada uma zona relativamente pobre em epífitas, seguida por uma zona intermediária bastante rica e da copa interna com significativa presença de pteridófitas. Considerando-se o aporte hídrico como o fator abiótico restritor mais relevante para o crescimento dessa flora (ZOTZ e HIETZ, 2001), é fácil imaginar por que galhos mais grossos e antigos, horizontais e protegidos de ventos e insolação diretos formem ambiente mais propício à flora epífita.

O número máximo de espécies sobre indivíduos forofíticos está de acordo com o padrão para a formação, sendo inferior a trabalhos em Floresta Ombrófila Densa (SCHUTZ-GATTI, 2000; KERSTEN e SILVA, 2001; 2005) e semelhante a trabalho na região de Guarapuava (KERSTEN et al., submetido). Nos trabalhos supracitados (exceto em Schutz-Gatti), as espécies a abrigarem maior comunidade epífita foram lauráceas do gênero Ocotea. Neste, uma leguminosa (Erythrina) ocupou este posto. Seu súber espesso e maleável, que lhe confere o nome de corticeira, influi em sua capacidade de armazenamento de água, que, somada ao seu porte, cria ambiente propício ao epifitismo.

Espécies pioneiras apresentam, em geral, crescimento rápido (SWAINE; WITHMORE, 1988), desenvolvem-se a pleno sol e são menos exigentes quanto às características de fertilidade do solo. Sendo as primeiras a crescerem, fecham o dossel e criam ambiente favorável às espécies mais seletivas, que as substituem nas séries seguintes. Considerando-se a comunidade epífita, os primeiros grupos a serem observados são os líquenes, seguidos das briófitas. Esses grupos aumentam a retenção de água da chuva, umidificando o ambiente (CLARK et al., 1998) e favorecendo o estabelecimento de espécies vasculares. Não obstante, as primeiras epífitas vasculares observadas em comunidades vegetais não são, via de regra, espécies exigentes. Poucas conseguem enfrentar os rigores de florestas com apenas um estrato arbóreo quase monoespecífico. Seu estabelecimento, aparentemente, não modifica o ambiente o suficiente para permitir a entrada de espécies avançadas ou climácicas. Alterações na comunidade arbórea, como enriquecimento, estratificação e maior cobertura do dossel, seriam responsáveis pelo recrutamento de novas espécies, sem necessária substituição, de diferentes epífitas vasculares.

Os resultados indicam que, em formações mais desenvolvidas, espécies pioneiras podem continuar ocorrendo, nem sempre apenas nas extremidades das copas. Podem ser menos importantes ou apresentarem menor dominância, mas, em geral, permanecem no ambiente enquanto outras são recrutadas à comunidade. É possível, inclusive, que permaneçam com dominância absoluta semelhante, e devido ao desenvolvimento das demais espécies, apresentem menor dominância relativa. Cabe ressaltar que a ocupação do ambiente epifítico só ocorre em estágios médios de recuperação da floresta (capoeiras e capoeirões, segundo classificação do IBGE, 1992). Locais observados em estágios iniciais de sucessão ou 
mesmo porções mais novas das estações levantadas não apresentaram epífitas vasculares, ou o epifitismo é incipiente.

Análises quantitativas associadas à observação de estações em diferentes estágios sucessionais permitiram a determinação de conjuntos de espécies característicos dos diferentes níveis de desenvolvimento das florestas em planície do Primeiro Planalto. As primeiras a aparecerem $(M$. squamulosa e $P$. pleopeltifolia), apesar de terem sido as principais espécies em todas as estações analisadas, foram bem mais importantes nas florestas jovens. São extremamente resistentes à desidratação e, como já citado, observadas em profusão, sobre árvores isoladas, mesmo em arborização urbana. Acompanhando-as, como pioneira, Capanemia australis (Orchidaceae) já foi registrada para florestas estacionais do Paraguai (observação pessoal), em regiões com até seis meses de seca por ano, demonstrando sua resistência ao déficit hídrico. Ainda no grupo das heliófilas iniciais, Polypodium hirsutissimum é notadamente poiquiloídrico. Além das copiosas escamas, tem notável capacidade de se desidratar e encolher, aparentando-se morta, mas facilmente retomando sua forma após precipitações.

Como pioneiras, são ainda observadas seis Orchidaceae, cinco Bromeliaceae, duas Polypodiaceae, duas Cactaceae e duas Piperaceae. No outro extremo, no grupo das esciófilas, estão as espécies observadas em locais mais bem conservados ou somente sobre árvores remanescentes. Entre estas estão 11 orquídeas, quatro bromélias, duas cactáceas e uma espécie de cada uma das famílias Hymenophyllaceae, Araceae, Dryopteridaceae, Gesneriaceae e Aspleniaceae. As espécies possivelmente mais associadas às florestas climácicas seriam: Asplenium incurvatum, Vriesea platynema, $V$. philippocoburgii e Barbosella australis. Estudos em outras bacias ou localidades com florestas melhor conservadas podem confirmar essa observação.

A comunidade de epífitas do Primeiro Planalto Paranaense é rica, apesar do alto nível de degradação imposto à maioria de suas florestas. As estações isoladamente, no entanto, apresentaram riqueza específica relativamente baixa, sendo caracterizadas como florestas secundárias em estágio médio de desenvolvimento. As espécies Campylocentrum burchellii, Capanemia australis e Campyloneurum austrobrasilianum, associadas a Peperomia catharinae, Pleurothallis hygrophila e Leptotes unicolor, além das duas espécies mais comuns e abundantes $M$. squamulosa e P. pleopeltifolia, podem ser consideradas diagnósticas dessas florestas. A região como um todo mostrou-se muito semelhante às localidades vizinhas, no município de Curitiba. Por sua vez, as estações individuais mostraram-se mais semelhantes entre si do que com os demais estudos no Brasil. Tanto a florística quanto a estrutura foram homogêneas ao longo do planalto, não sendo observadas alterações significativas na flora epífita, mesmo entre extremos. As estações de floresta de encosta foram mais ricas que as de planície e apresentaram flora diferenciada. As florestas em estágio inicial de desenvolvimento apresentaram riqueza e diversidade inferiores às da floresta em estágio médio, não sendo registradas áreas em estágio avançado de desenvolvimento. As duas espécies mais importantes destacaram-se das demais, reforçando o caráter secundário das florestas analisadas. Quatro espécies (Pleopeltis pleopeltifolia, Microgramma squamulosa, Capanemia australis e Polypodium hirsutissimum) compõem a frente inicial de colonização do ambiente epifítico, enquanto outras 15 espécies podem também ser consideradas pioneiras.

\section{REFERÊNCIAS}

BARBOSA, L. M. Estudos interdisciplinares do Instituto de Botânica em Moji-Guaçu, SP. In SIMPÓSIO SOBRE MATA CILIAR, 1989, São Paulo. Anais... São Paulo: Fundação Cargill. 1989. p. 171-191.

BENZING, D. H. Vascular epiphytes. Cambridge. Cambridge University Press, 1990.

BORGO, M.; SILVA S. M. Epífitos vasculares em fragmentos de Floresta Ombrófila Mista, Curitiba, Paraná, Brasil. Revista Brasileira de Botânica, São Paulo, n. 26, p. 391-401, 2003.

BORGO, M.; SILVA, S. M.; PETEAN, M. Epífitos vasculares em um remanescente de floresta estacional semidecidual, município de Fênix, PR, Brasil. Acta Biológica Leopoldensia, São Leopoldo, n. 24, p. 121-130, 2002.

BRAUN-BLANQUET, J. Fitossociologia: bases para el estudio de las comunidades vegetales. Madrid: H. Blume, 1979. 
CASTElA, P. R.; BRITEZ, R. M. A floresta com Araucária no estado do Paraná. Brasília, DF: Ministério do Meio Ambiente, 2004.

CERVI, A. C.; ACRA, L. A.; RODRIGUES, L.; TRAIN, S.; IVANCHECHEN, S. L.; MOREIRA, A. L. O. R. Contribuição ao conhecimento das epífitas (exclusive Bromeliaceae) de uma floresta de araucária do primeiro planalto paranaense. Ínsula, Florianópolis, v. 18, p. 75-82, 1988.

CERVI, A. C.; DOMBROWSKI, L. T. D. Bromeliaceae de um capão de floresta primária do Centro Politécnico de Curitiba (Paraná, Brasil). Fontqueria, Madrid, v. 9, p. 9-11, 1985.

CIRELliI, K. R. T.; PENTEADO-DIAS A. M. Análise da riqueza da fauna de Braconidae (Hymenoptera, Ichneumonoidea) em remanescentes naturais da Área de Proteção Ambiental (APA) de Descalvado, SP. Revista Brasileira de Entomologia, São Paulo, v. 47, p. 89-98, 2003.

CLARK, K. L.; NADKARNI, N. M.; SCHARFER, D.; GHOLZ, H. L. Atmosferic deposition and net retention of ions by the canopy in a tropical montane forest, Monteverde, Costa Rica. Journal of Tropical Ecology, Cambridge, v. 14, p. 27-45, 1998.

CURCIO, G. Caracterização geomorfologica, pedológica e fitossociológica das planícies fluviais do Iguaçu, Paraná, Brasil. Tese (Doutorado em Engenharia Florestal) - Setor de Ciências Agrárias, Universidade Federal do Paraná. Curitiba, 2006.

DITTRICH, V. A. O.; KOZERA C.; SILVA, S. M. Levantamento florístico dos epífitos vasculares do parque Barigüi. Paraná - Brasil. Iheringia. Série Botânica, Porto Alegre, v. 52, p. 11-21, 1999.

FREIBERG, M. Spatial distribution of vascular epiphytes on three emergent canopy trees in French Guiana. Biotropica, Washingtom, DC, n. 28, p. 345-355, 1996.

GENTRY, A. H.; DODSON, C. H. Diversity and biogeography of neotropical vascular epiphytes. Annals of Missouri Botanical Garden, [S.1.], v. 74, p. 205-223, 1987.

GIONGO, C.; WAECHTER J. L. Composição florística e estrutura comunitária de epífitos vasculares em uma floresta de galeria na Depressão Central do Rio Grande do Sul. Revista Brasileira de Botânica, São Paulo, n. 27, p. 563-572, 2004.

GONÇALVES, C. N.; WAECHTER, J. L. Epífitos vasculares sobre espécimes de Ficus organensis isolados no norte da planície costeira do Rio Grande do Sul: Padrões de abundância e distribuição. Acta Botanica Brasílica, Porto Alegre, v. 16, p. 429-441, 2002.

INSTITUTO BRASILEIRO DE GEOGRAFIA E ESTATÍSTICA (IBGE). Manual técnico da vegetação brasileira. Rio de Janeiro, 1992.

INGRAM, S. W.; NADKARNI, N. M. Composition and distribution of epiphytic organic matter in a neotropical cloud forest, Costa Rica. Biotropica, Washingtom, DC, n. 25, p. 370-383, 1993.

JOHANSSON, D. R. Ecology of vascular epiphytes in West African rain forest. Acta Phytogeographyca Suecica, [S.1.], v. 59, p. 1-136, 1974.

KERSTEN, R. A. Epifitismo vascular na bacia do alto Iguaçu, Paraná. Tese (Doutorado em Engenharia Florestal) - Setor de Ciências Agrárias, Universidade Federal do Paraná. Curitiba, 2006.

KERSTEN, R. A.; SILVA, S. M. Composição florística e distribuição espacial de epífitas vasculares em floresta da planície litorânea da Ilha do Mel, Paraná, Revista Brasileira de Botânica, São Paulo, n. 24, p. 213-226, 2001.

KERSTEN, R. A.; SILVA, S. M. Florística e estrutura do componente epifítico vascular em Floresta Ombrófila Mista aluvial do rio Barigüi, Paraná, Brasil. Revista Brasileira de Botânica, São Paulo, n. 25, p. 259-267, 2002.

KERSTEN, R. A.; SILVA, S. M. Florística e estrutura de comunidades de epífitas vasculares da planície litorânea. In: MARQUES, M. C. M; BRITEZ, R. M. (Org.) História natural e conservação da Ilha do Mel. Curitiba: Ed. da Univ. Federal do Paraná,. p. 125-144, 2005. 
KERSTEN, R. A.; SILVA, S. M. Brasil. The Floristic Composition of Vascular Epiphytes of a Seasonally Inundated Forest on the Coastal Plain of Ilha do Mel Island, Brazil, Revista de Biología Tropical, San Jose, v. 54, p. 935-942, 2006.

KERSTEN, R. A.; KUNIYOSHI, Y. S.; RODERJAN, C. V. no prelo. Comunidade epífita em duas formações florestais do Rio São Jerônimo, Bacia do Rio Iguaçu, municípios de Guarapuava e Pinhão, Paraná. Iheringia. Série Botânica, Porto Alegre.

KRESS, J. W. The systematic distribution of vascular epiphytes: an update. Selbyana, Sarasota, v. 9, p. 2-22, 1986.

LIMA, W. P.; ZAKIA, M. J. B. Hidrologia de matas ciliares. In: RODRIGUES, R.R.; LEITÃO-FILHO, H.F. (Org.). Matas ciliares: conservação e recuperação. São Paulo: Edusp/Fapesp, 2000. p. 33-44.

MAACK, R. Geografia física do estado do Paraná. Curitiba: BADEP/UFPR/IBPT, 1968.

MAGURRAN, A. E. Measuring Biological Diversity. Londres: Wiley-Blackwell, 2004.

NIEDER, J.; PROSPERÍ, J.; MICHALOUD, G. Epiphytes and their contribution to canopy diversity. Plant Ecology, Dordrecht, v. 153, p. 51-63, 2001.

PETEAN, M. P. Florística e estrutura dos epífitos vasculares em uma área de Floresta Ombrófila Densa Altomontana no Parque Estadual do Pico do Marumbi, Morretes, Paraná, Brasil. Dissertação (Mestrado em Botânica) - Setor de Ciências Biológicas, Universidade Federal do Paraná, Curitiba, 2003.

ROGALSKI, J. M.; ZANIN E. M. Composição florística de epífitos vasculares no estreito de Augusto César, Floresta Estacional Decidual do Rio Uruguai, RS, Brasil. Revista Brasileira de Botânica, São Paulo, n. 26, p. 551-556, 2003.

SCHÜTZ-GATTI, A. L. O componente epifítico vascular na Reserva Salto Morato, Guaraqueçaba. PR. Dissertação (Mestrado em Botânica) - Setor de Ciências Biológicas, Universidade Federal do Paraná, Curitiba, 2000.

SMITH, A. R.; PRYER, M. K.; SCHUETTPELZ E.; KORALL, P.; SCHNEIDER, H.; WOLF, P. G. A classification for extant ferns. Taxon, Utracht, v. 55, p. 705-731, 2006.

STEVENS, P. F. 2006. Angiosperm Phylogeny Website. Disponível em: <http://www.mobot.org/MOBOT/research/APweb/>. Acesso em: 22/05/2006.

SUDGEN, A. M.; ROBINS, R. J. Aspects of the ecology of vascular epiphytes in Colombian Cloud Forests, I. distribution of the epiphytic flora. Biotropica, Washingtom, DC, n. 11, p. 173-188, 1979.

SWAINE, M. D. WHITMORE, T. C. On the definition of the ecological species groups in tropical rain forests. Vegetatio, The Hague, n. 75, p. 81-86, 1988.

TRIANA-MORENO, L. A.; GARZÓN-VENEGAS, N. J.; SÁNCHEZ-ZAMBRANO, J.; VARGAS, O. Epífitas vasculares como indicadores de regeneración enbosques intervenidos de la amazonía Colombiana. Acta Biológica Colombiana, Bogotá, n. 8, p. 31-42, 2003.

VAN DEN BERG, E.; OLIVEIRA FILHO, A. T. Composição florística e estrutura fitossociológica de uma floresta ripária em Itutinga, MG, e comparação com outras áreas. Revista Brasileira de Botânica, São Paulo, n. 23, p. 231-253., 2000.

W3TROPICOS. Vascular Tropicos Nomenclatural database. Disponível em: <http://mobot.mobot.org/W3T/Search/vast.html> Acesso em: 12/06/2006.

WAECHTER, J. L.; BAPTISTA, L. R. M. Abundância e distribuição de orquídeas epifíticas em uma floresta turfosa do Brasil Meridional.. In: BARROS, F. de; KERBAUY, G. B. (Org.). Orquideologia sulamericana: uma compilação científica. São Paulo: Secretaria do Meio Ambiente, Instituto de Botânica, 2004. p. 135-145.

WAECHTER, J. L. O epifitismo vascular na planície costeira do Rio Grande do Sul. Tese (doutorado em Ecologia) - Universidade Federal de São Carlos, São Carlos, 1992. 
WAECHTER, J. L. Epifitismo vascular em uma floresta de restinga do Brasil Subtropical. Revista Ciência e Natura, Santa Maria, n. 20, p. 43-66, 1998.

WOLF, J. H. D. The response of epiphytes to anthropogenic disturbance of pine-oak forests in the highlands of Chiapas, México. Forest Ecology and Management, Amsterdam, v. 212, p. 376-393. 2005.

ZOTZ, G.; HIETZ, P. The physiological ecology of vascular epiphytes: current knowledge, open questions. Journal of Experimental Botany, Oxford, n. 52, p. 2067-2078, 2001. 